\title{
SECONDHAND SMOKE EXPOSURE WITHIN SEMI-OPEN AIR CAFES AND TOBACCO SPECIFIC 4-(METHYLNITROSAMINO)-1-(3- PYRIDYL)-1-BUTANOL (NNAL) CONCENTRATIONS AMONG NONSMOKING EMPLOYEES
}

\section{CONSTANTINE I. VARDAVAS ${ }^{1,2}$, MARIA KARABELA ${ }^{2}$, ISRAEL T. AGAKU ${ }^{1}$, YUKO MATSUNAGA ${ }^{1}$, ANTONIS MYRIDAKIS ${ }^{3}$, ANTONIS KOUVARAKIS ${ }^{3}$, EURIPIDES G. STEPHANOU ${ }^{3}$, MARIA LYMPERI ${ }^{4}$, and PANAGIOTIS K. BEHRAKIS ${ }^{2,4,5}$}

${ }^{1}$ Harvard School of Public Health, Boston, MA, USA

Department of Social and Behavioral Sciences, Center for Global Tobacco Control

${ }^{2}$ Hellenic Cancer Society, Athens, Greece

Smoking and Lung Cancer Research Center

${ }^{3}$ University of Crete, Crete, Greece

Department of Chemistry, Environmental Chemical Processes Laboratory (ECPL)

${ }^{4}$ University of Athens, Athens, Greece

Medical School

${ }^{5}$ Harvard School of Public Health, Boston, MA, USA

Department of Environmental Health

\begin{abstract}
Objectives: Secondhand smoke (SHS) is a defined occupational hazard. The association though between SHS exposure in semiopen air venues and tobacco specific carcinogen uptake is an area of debate. Material and Methods: A cross sectional survey of 49 semi-open air cafes in Athens, Greece was performed during the summer of 2008, prior to the adoption of the national smoke free legislation. All venues had at least 1 entire wall open to allow for free air exchange. Indoor concentrations of particulate matter smaller than 2.5 microns $\left(\mathrm{PM}_{25}\right)$ attributable to SHS were assessed during a work shift, while 1 non-smoking employee responsible for indoor and outdoor table service from each venue provided a post work shift urine sample for analysis of 4-(methylnitrosamino)1-(3-pyridyl)-1-butanol (NNAL). Results: Post work shift NNAL concentrations were correlated with work shift $\mathrm{PM}_{25}$ concentrations attributable to SHS $(r=0.376, p=0.0076)$. Urinary NNAL concentrations among employees increased by $9.5 \%$, per $10 \mu \mathrm{g} / \mathrm{m}^{3}$ increase in $\mathrm{PM}_{25}$ concentrations attributable to SHS after controlling for the time of day and day of week. Conclusions: These results indicate that the commonly proposed practice of maintaining open sliding walls as a means of free air exchange does not lead to the elimination of employee exposure to tobacco specific carcinogens attributable to workplace SHS.
\end{abstract}

Key words:

$\mathrm{PM}_{25}$, Occupational exposure, NNAL, Second hand smoke, Hospitality venue, Semi open

Received: October 25, 2013. Accepted: May 16, 2014

Corresponding author: C.I. Vardavas, Center for Global Tobacco Control, Department of Social and Behavioral Sciences, Harvard School of Public Health, 401 Park Drive Landmark Center 4th Floor, Boston, MA 02215, USA (e-mail: vardavas@hsph.harvard.edu). 


\section{INTRODUCTION}

Tobacco specific nitrosamines (TSNAs) are major carcinogens in tobacco and are formed from tobacco alkaloids during the curing, fermentation and ageing of tobacco leaves [1]. One of the most extensively investigated TSNAs in tobacco products is NNK (4-(methylnitrosamino)-1-(3-pyridyl)-1-butanone), a potent carcinogen that is metabolized in the liver to form NNAL (4-(methylnitrosamino)-1-(3-pyridyl)1-butanonol) [2,3]. NNAL concentrations within subjects have been associated with a higher risk for developing lung cancer among smokers, indicating its use as a biomarker of lung cancer risk among smokers [4,5]. While research has extensively associated secondhand smoke (SHS) concentrations with particulate matter less than 2.5 microns $\left(\mathrm{PM}_{2.5}\right)$ and human biomarkers, the impact of occupational exposure to SHS in semiopen cafes and TSNA uptake remains relatively unexplored [6-8].

In countries with warm climates, open sliding walls are commonly used to expand the size of cafe/bars and allow for the free interaction of music and people between indoor and outdoor areas. Within Mediterranean countries that pose a strong tourist destination - such as Greece, Italy and Spain - these semi-open venues take advantage of the mild Mediterranean climate, which allows the use of such outdoor areas during most of the year [9]. During the timeframe of this study smoking in public places was not legislated in Greece, which led to extensive exposure to SHS within the hospitality industry [10]. However, during the negotiation phase of the subsequent smoke free legislations, the impact of maintaining open windows or sliding walls was brought forward as a method of reducing population exposure to SHS. Our hypothesis was that such a practice would still lead to increased urinary NNAL concentrations among employees that work in these semi-open areas. Hence, the aim of the study was to investigate the association between exposure to SHS within semi-open hospitality venues and post work shift NNAL concentrations among non-smoking employees.

\section{MATERIAL AND METHODS}

\section{Study setting - air monitoring}

A convenience sample of 50 venues was selected in Athens, Greece prior to the implementation of the 2010 smoking ban, during the summer months of May-June 2008. Due to the lack of a comprehensive list of all hospitality venues in Athens, a convenience sample of venues was selected based on if they had open sliding walls, thus allowing for air exchange between the indoor and outdoor areas of the venue. SHS concentrations were measured with a TSI SidePak AM510 Personal Aerosol Monitor (TSI, Inc., St. Paul, Minnesota, USA) which recorded levels of $\mathrm{PM}_{2.5}$, attributable to SHS. While $\mathrm{PM}_{2.5}$ is not generated only by SHS exposure, and may be generated by other sources such as candles, open fires or cooking, we excluded from the sample any venue with such parameters according to standardised methodology for assessing $\mathrm{PM}_{2.5}$ attributable to SHS (flow rate of $1.7 \mathrm{l} / \mathrm{min}$ and calibration factor 0.32) [8,9]. Baseline outdoor levels of $\mathrm{PM}_{25}$ were also measured (an average of $12 \mu \mathrm{g} / \mathrm{m}^{3}$ ) and subtracted from indoor concentrations. The TSI Sidepack AM510 was set to a $1 \mathrm{~s} \log$ interval, which data-logged the real-time $\mathrm{PM}_{2.5}$ measurement per second. Sampling took place between 12 a.m. - 12 p.m., while air monitoring was performed for at least $30 \mathrm{~min}$ in all venues. In each venue the average number of burning cigarettes and the room volume were noted so as to calculate "smoker density," the quotient of the average number of burning cigarettes per $100 \mathrm{~m}^{3}$ of room volume.

Following written informed consent, one non-smoking employee from each venue was requested to provide a urine sample at the end of their $8 \mathrm{~h}$ shift, on the same day in which the SHS concentrations were measured. 
Non-smoker status was cross evaluated by both self-report, and biomarker verification with the cut-off urinary cotinine level for smoking designated at $100 \mathrm{ng} / \mathrm{ml}$, a cutoff identified to be most appropriate for the population through prior population based studies [11]. Approval to conduct the survey was granted by the Ethical Committee of the University of Athens. Further details and exposure assessment of the current study can be found elsewhere [12].

\section{NNAL analysis}

The analytical procedure for total NNAL (free and conjugated) was based on Supelco procedure, under minor modifications (Supelco SupelMIP SPE - NNAL Instruction). Urine samples were thawed, vortex mixed and $5 \mathrm{ml}$ dispensed into a $15 \mathrm{ml}$ falcon tube. For the hydrolysis of conjugated NNAL, were added $50 \mu$ l of enzyme $\beta$-Glucoronidase (Escherichia coli-K12 version 4.0, Roche Biomedical, Mannheim, Germany) and $10 \mathrm{ml} 50 \mathrm{mM}$ ammomium dihydrogen phosphate buffer, $\mathrm{pH}=6.4$. The samples were incubated for $48 \mathrm{~h}$ at $37^{\circ} \mathrm{C}$. The SupelMIP-NNAL cartridges were conditioned with $1 \mathrm{ml}$ dichloromethane, $1 \mathrm{ml}$ methanol and $1 \mathrm{ml}$ water prior the sample loading. The cartridges were washed with $2 \times 1 \mathrm{ml}$ water, $1 \mathrm{ml}$ toluene, $1 \mathrm{ml}$ toluene:dichloromethane $(9: 1, \mathrm{v} / \mathrm{v}), 1 \mathrm{ml}$ toluene:dichloromethane $(4: 1, \mathrm{v} / \mathrm{v})$ and the analyte was eluted with $2 \times 1 \mathrm{ml}$ dichloromethane:methanol (9:1, v/v). Samples were concentrated to dryness using a vacuum centrifuge (rotational vacuum concentrator, RVC 2-25 Martin Christ, Germany) and reconstituted to $500 \mu \mathrm{l}$ of HPLC mobile phase ( $10 \mathrm{mM}$ ammonium formate, $\mathrm{pH}=6.1)$.

Instrumental analysis was performed on an LC-MS/MS system. The chromatographic separation was achieved using a Thermo Finnigan Surveyor LC system (Thermo Finnigan, San Jose, USA), equipped with a Gemini C18 $(3 \mu \mathrm{m}, 100 \mathrm{~mm} \times 2 \mathrm{~mm})$ analytical column by Phenomenex (Torrance, USA). The mass detection was achieved with a TSQ Quantum triple quadrupole with ESI source operated in positive mode (Thermo Finnigan, San Jose, USA). The system was controlled by the Xcalibur software, which was also used for the data acquisition and analysis. Method limit of detection (signal to noise ratio equal to 3) was $4.4 \mathrm{pg} / \mathrm{ml}$ and method limit of quantitation (signal to noise ratio equal to 10 ) was $5.3 \mathrm{pg} / \mathrm{ml}$.

\section{Statistical analysis}

The 4-(methylnitrosamino)-1-(3-pyridyl)-1-butanol levels were summarized using geometric means with $95 \%$ confidence intervals, arithmetic means with standard deviations, as well as medians and ranges. In cases where the result was below the limit of detection, the value for that variable was the detection limit divided by the square root of 2 .

A Spearman's correlation coefficient was calculated for the unadjusted relationship between NNAL levels and $\mathrm{PM}_{2.5}$. The partial correlation between NNAL levels and $\mathrm{PM}_{2.5}$ was also calculated, adjusting for time of day and day of week. The degree of variation of NNAL that could be attributable to $\mathrm{PM}_{2.5}$ changes was assessed using ANOVA with $\mathrm{PM}_{2.5}$ levels categorized as < 50; 50-150 and $>150 \mu \mathrm{g} / \mathrm{m}^{3}$. Within the analyses the time of day was assessed as either before 8 p.m. or after 8 p.m. (daytime vs. night time), while the day of week was categorized as either a weekday (Monday to Thursday) or a weekend (Friday-Sunday). In the regression analyses, NNAL was transformed to the natural log scale to assume a normal distribution and adjusting for time of day and day of week (factors found in previous air monitoring studies in Greece to influence $\mathrm{PM}_{2.5}$ concentrations attributable to SHS) [8]. Analyses were performed with SAS (SAS Institute, Cary, NC).

\section{RESULTS}

The association between age, gender, time of day and day of week and urinary NNAL concentrations are depicted in Table 1. Within the bivariate analysis, NNAL concentrations of urine samples collected from patrons 
Table 1. The 4-(methylnitrosamino)-1-(3-pyridyl)-1-butanol (NNAL) concentrations among non-smoking employees exposed to secondhand smoke in semi-open air venues by sampling characteristic

\begin{tabular}{|c|c|c|c|c|c|}
\hline \multirow{2}{*}{ Characteristic } & \multirow{2}{*}{$\begin{array}{l}\text { Respondents } \\
\text { (n) }\end{array}$} & \multicolumn{3}{|c|}{$\begin{array}{c}\text { NNAL concentrations } \\
(\mathrm{pg} / \mathrm{ml})\end{array}$} & \multirow{2}{*}{$\mathrm{p}$} \\
\hline & & $\mathrm{AM} \pm \mathrm{SD}$ & GM $(95 \% \mathrm{CI})$ & $\begin{array}{c}\mathrm{Me} \\
\text { (range) }\end{array}$ & \\
\hline Overall population & 49 & $85.82 \pm 117.61$ & $33.10(20.28-54.02)$ & $44.0(1.41-673)$ & \\
\hline Sex & & & & & 0.886 \\
\hline male & 25 & $96.96 \pm 149.65$ & $29.39(13.54-63.81)$ & $43.0(1.41-673)$ & \\
\hline female & 24 & $74.22 \pm 72.29$ & $37.46(19.58-71.67)$ & $56.5(1.41-271)$ & \\
\hline Age (years) & & & & & 0.400 \\
\hline$\leq 30$ & 22 & $102.42 \pm 102.42$ & $40.35(18.93-86.02)$ & $51.0(1.41-673)$ & \\
\hline $31-44$ & 17 & $51.59 \pm 69.98$ & $15.82(6.1-41.03)$ & $18.0(1.41-218)$ & \\
\hline$\geq 45$ & 10 & $107.50 \pm 106.05$ & $75.05(40.53-138.96)$ & $71.0(24-333)$ & \\
\hline Time of day & & & & & 0.549 \\
\hline day time (before 8 p.m.) & 37 & $82.84 \pm 121.28$ & $31.53(17.7-56.19)$ & $44.0(1.41-673)$ & \\
\hline night-time (after 8 p.m.) & 12 & $95.03 \pm 110$ & $38.42(13.17-112.12)$ & $49.0(1.41-333)$ & \\
\hline Day of week & & & & & 0.733 \\
\hline weekend (Friday-Sunday) & 32 & $91.28 \pm 134.87$ & $27.83(13.97-55.44)$ & $39.5(1.41-673)$ & \\
\hline other (Monday-Thursday) & 17 & $75.55 \pm 78.01$ & $45.85(24.54-85.7)$ & $49.0(1.41-333)$ & \\
\hline $\mathrm{PM}_{2.5}$ concentration $\left(\mu \mathrm{g} / \mathrm{m}^{3}\right)$ & & & & & 0.197 \\
\hline$<50$ & 11 & $44.63 \pm 28.13$ & $33.41(14.69-76.06)$ & $43.5(4-96)$ & \\
\hline $50-150$ & 28 & $96.70 \pm 74.72$ & $70.30(48.50-101.89)$ & $78.0(12-271)$ & \\
\hline$>150$ & 10 & $161.30 \pm 212.23$ & $72.37(26.33-198.90)$ & $67.0(7.0-673.0)$ & \\
\hline
\end{tabular}

$\mathrm{AM}$ - arithmetic mean; SD - standard deviation; GM - geometric mean; CI - confidence interval; Me - median.

that worked during night shifts were slightly higher than those that worked day shifts $(95.03 \mathrm{pg} / \mathrm{ml}$ vs. $82.84 \mathrm{pg} / \mathrm{ml})$ as were samples taken during the weekend vs. weekday (91.28 pg/ml vs. $75.5 \mathrm{pg} / \mathrm{ml})$.

Mean NNAL concentrations were significantly higher among employees within cafe/bars that had $\mathrm{PM}_{2.5}$ concentrations attributable to SHSgreater than $150 \mu \mathrm{g} / \mathrm{m}^{3}$, in comparison to venues that had $\mathrm{PM}_{2.5}$ concentrations $<50 \mu \mathrm{g} / \mathrm{m}^{3}$ (161.3 pg/ml vs. $44.63 \mathrm{pg} / \mathrm{ml}, \mathrm{p}=0.012$ ). However, no statistically significant difference in post work shift NNAL concentrations was noticed between employees in cafe/bars with $\mathrm{PM}_{2.5}$ concentrations $<50 \mu \mathrm{g} / \mathrm{m}^{3}$ vs. those with $\mathrm{PM}_{2.5}$ concentrations of $50-150 \mu \mathrm{g} / \mathrm{m}^{3}(\mathrm{p}=0.245)$, or between employees in venues with $\mathrm{PM}_{2.5}$ concentrations of $50-150 \mu \mathrm{g} / \mathrm{m}^{3}$ vs. $>150 \mu \mathrm{g} / \mathrm{m}^{3}(\mathrm{p}=0.054)$.

Controlling for the time of day and day of the week when sampling took place, urinary NNAL concentrations were correlated with both urinary cotinine concentrations $(\mathrm{r}=0.371, \mathrm{p}<0.01)$ and with indoor $\mathrm{PM}_{2.5}$ concentrations attributable to SHS $(r=0.378, p<0.01)$, however no statistically significant correlation between smoker density and urinary NNAL levels $(r=0.201, p=0.166)$ or smoker density and $\mathrm{PM}_{2.5}$ was noted $(\mathrm{r}=0.200, \mathrm{p}=0.209)$. Finally, within the context of a linear regression analysis controlling for the time of the day and the day of the week, for each $10 \mu \mathrm{g} / \mathrm{m}^{3}$ increase in indoor $\mathrm{PM}_{2.5}$ concentrations, 
urinary post workshift NNAL concentrations increased by $9.5 \%$. (Beta per $10 \mu \mathrm{g} / \mathrm{m}^{3}$ increase in $\mathrm{PM}_{2.5}: 0.095$, 95\% CI: 0.03 to $0.16, p=0.005$.)

\section{DISCUSSION}

Our results indicate that the practice of maintaining sliding walls of semi-open venues may be associated with elevated TSNA uptake among non-smoking employees. Specifically, we identified that per $10 \mu \mathrm{g} / \mathrm{m}^{3}$ increase in $\mathrm{PM}_{2.5}$ concentrations within quasi-open areas, urinary NNAL concentrations among employees increased respectively by $9.5 \%$. The 4-(methylnitrosamino)-1-(3-pyridyl)-1-butanol concentrations among hospitality venue employees have been previously correlated with exposure to indoor SHS, and absolute levels have been found to decrease following the implementation of a smoke free legislation, from $0.086 \mathrm{pmol} / \mathrm{ml}$ to $0.034 \mathrm{pmol} / \mathrm{ml}$ [13].

Furthermore, employees exposed to indoor workplace SHS are more likely to have higher mean levels of NNAL compared with non-exposed participants, with NNAL concentrations associated with the hours of employee exposure [14]. While significant research has focused on the effect of SHS exposure on TSNA uptake in indoor areas, only one study to date has assessed TSNA uptake in relationship to SHS exposure in outdoor areas, which indicated that exposure to SHS in outdoor air settings increased urinary NNAL concentrations [7]. Our findings identified an association between exposure to SHS in semi open areas and NNAL concentrations, a novel association, within a situation very common in warm Mediterranean environments.

A number of factors have been identified to influence exposure to SHS within indoor and outdoor settings such as the number of cigarettes being smoked, the position of smokers relative to the measurement device (or subject) and wind conditions, which can lead to substantial variation in average exposures [6]. The clustering of smokers (i.e., smoker density) noted within a busy semi-open air venue may potentially lead to higher $\mathrm{PM}_{2.5}$ concentrations, a fact which we noted previously in previous research among this specific group of employees to be associated with urinary cotinine concentrations [12], however we did not identify such an association between smoker density and NNAL concentrations within this analysis. It is likely that the difference in the clearance half-life of cotinine vs. NNAL may be responsible for this discrepancy, or that the usefulness of "smoker density" as an index of exposure is limited.

As the employees in this study would service the entire venue (both the semi open and outdoor areas) we were unable to assess the effect of proximity to cigarettes, which may have further impacted the employees' exposure. Previous research performed within hospitality venues in Greece indicated that indoor $\mathrm{PM}_{2.5}$ concentrations attributable to SHS were associated with the time of day (before 8 p.m. vs. after 8 p.m.) and the day of the week (weekend vs. weekday) [8]. Using NNAL as a direct biomarker of exposure to SHS, we found increased NNAL concentrations among employees assessed during the evenings and on weekends; however, none of these differences reached the level of statistical significance. Further research into the factors that affect NNAL concentrations among employees in semi-open air settings is thus needed. Due to organizational limitations we were unable to collect pre work shift urine samples so as to assess the mean change in NNAL concentrations or assess baseline exposure to SHS, which are limitations of our current study. However, i) as NNAL concentrations have been identified to rapidly increase and peak after 4-8 h following $1 \mathrm{st}$ exposure and ii) as the current measurements were performed after an $8 \mathrm{~h}$ shift during which the employees were exposed to SHS, we anticipate that the NNAL concentrations would be mainly attributable to their concurrent occupational exposure [15]. Any discrepancies in baseline SHS exposure would err towards the null hypothesis 
and thus strengthen our findings. Moreover, as the study was conducted among a convenience sample of venues in Athens, Greece, its generalizability to exposure in other venues in Athens is limited.

\section{CONCLUSIONS}

This study identified an association between occupational exposure to SHS within semi-open cafe/bars and TSNA concentrations among non-smoking employees. These results potentially refute the commonly debated and proposed practice of maintaining open sliding walls as a means of free air exchange as this does not lead to the elimination of employee exposure to tobacco specific carcinogens attributable to occupational SHS.

\section{REFERENCES}

1. Hatsukami DK, Lemmonds C, Zhang Y, Murphy SE, Le C, Carmella SG, et al. Evaluation of carcinogen exposure in people who used "reduced exposure" tobacco products. J Natl Cancer Inst. 2004;96(11):844-52, http://dx.doi.org/10.1093/ jnci/djh163.

2. Stanfill SB, Connolly GN, Zhang L, Jia LT, Henningfield JE, Richter P, et al. Global surveillance of oral tobacco products: Total nicotine, unionised nicotine and tobacco-specific N-nitrosamines. Tob Control. 2011;20(3):e2, http:/dx.doi. org/10.1136/tc.2010.037465.

3. Upadhyaya P, Carmella SG, Guengerich FP, Hecht SS. Formation and metabolism of 4-(methylnitrosamino)-1-(3pyridyl)-1-butanol enantiomers in vitro in mouse, rat and human tissues. Carcinogenesis. 2000;21(6):1233-8, http://dx.doi. org/10.1093/carcin/21.6.1233.

4. Yuan JM, Koh WP, Murphy SE, Fan Y, Wang R, Carmella SG, et al. Urinary levels of tobacco-specific nitrosamine metabolites in relation to lung cancer development in two prospective cohorts of cigarette smokers. Cancer Res. 2009;69(7): 2990-5, http://dx.doi.org/10.1158/0008-5472.CAN-08-4330.
5. Derby KS, Cuthrell K, Caberto C, Carmella S, Murphy SE, Hecht SS, et al. Exposure to the carcinogen 4-(methylnitrosamino)-1-(3-pyridyl)-1-butanone (NNK) in smokers from 3 populations with different risks of lung cancer. Int J Cancer. 2009;125(10):2418-24, http://dx.doi.org/ 10.1002/ijc.24585.

6. Sureda X, Fernandez E, Lopez MJ, Nebot M. Secondhand tobacco smoke exposure in open and semi-open settings: A systematic review. Environ Health Perspect. 2013;121(7): 766-73, http://dx.doi.org/10.1289/ehp.1205806.

7. St Helen G, Bernert JT, Hall DB, Sosnoff CS, Xia Y, Balmes JR, et al. Exposure to secondhand smoke outside of a bar and a restaurant and tobacco exposure biomarkers in nonsmokers. Environ Health Perspect. 2012;120(7):1010-6, http://dx.doi.org/10.1289/ehp.1104413.

8. Lopez MJ, Fernandez E, Gorini G, Moshammer H, Polanska K, Clancy L, et al. Exposure to secondhand smoke in terraces and other outdoor areas of hospitality venues in eight European countries. PLoS One. 2012;7(8):e42130, http:// dx.doi.org/10.1371/journal.pone.0042130.

9. Vardavas CI, Kafatos A. Greece's tobacco policy: Another myth? Lancet. 2006;367(9521):1485-6, http://dx.doi. org/10.1016/S0140-6736(06)68646-7.

10. Vardavas CI, Anagnostopoulos N, Patelarou E, Minas M, Nakou C, Dramba V, et al. Five-year trends of secondhand smoke exposure in Greece: A comparison between complete, partial, and prelegislation levels. J Aerosol Med Pulm Drug Deliv. 2012 Dec;25(6):349-54, http://dx.doi. org/10.1089/jamp.2011.0949.

11. Vardavas CI, Fthenou E, Patelarou E, Bagkeris E, Murphy S, Hecht SS, et al. Exposure to different sources of second-hand smoke during pregnancy and its effect on urinary cotinine and tobacco-specific nitrosamine (NNAL) concentrations. Tob Control. 2013 May;22(3):194-200, http:// dx.doi.org/10.1136/tobaccocontrol-2011-050144.

12. Karabela M, Vardavas CI, Tzatzarakis M, Tsatsakis A, Dockery D, Connolly GN, et al. The relationship between venue indoor air quality and urinary cotinine 
levels among semiopen-air cafe employees: What factors determine the level of exposure? J Aerosol Med Pulm Drug Deliv. 2011;24(1):35-41, http://dx.doi.org/10.1089/ jamp.2010.0837.

13. Wilson T, Shamo F, Boynton K, Kiley J. The impact of Michigan's Dr Ron Davis smoke-free air law on levels of cotinine, tobacco-specific lung carcinogen and severity of self-reported respiratory symptoms among non-smoking bar employees. Tob Control. 2012;21(6):593-5, http://dx.doi.org/10.1136/ tobaccocontrol-2011-050328.
14. Stark MJ, Rohde K, Maher JE, Pizacani BA, Dent CW, Bard R, et al. The impact of clean indoor air exemptions and preemption policies on the prevalence of a tobacco-specific lung carcinogen among nonsmoking bar and restaurant workers. Am J Public Health. 2007;97(8):1457-63, http:// dx.doi.org/AJPH.2006.094086.

15. Jones IA, St Helen G, Meyers MJ, Dempsey DA, Havel C, Jacob P 3rd, et al. Biomarkers of secondhand smoke exposure in automobiles. Tob Control. 2013;23(1):51-7, http:// dx.doi.org/10.2105/AJPH.2006.094086.

This work is available in Open Access model and licensed under a Creative Commons Attribution-NonCommercial 3.0 Poland License - http://creativecommons.org/ licenses/by-nc/3.0/pl/deed.en. 